\title{
Recent Developments on Surfactants for Enhanced Oil Recovery
}

This review discusses surfactants used for chemical flooding, including surfactant-polymer flooding and alkali-surfactant-polymer flooding. The review, unlike most previous reviews in the field, has a surfactant focus, not a focus on the flooding process. It deals with recent results, mainly from 2010 and onward. Older literature is referred to when needed in order to put more recent findings into a perspective.

Keywords: Enhanced oil recovery, surfactant flooding, microemulsion, Winsor system, interfacial tension

\begin{abstract}
Neueste Entwicklungen bei Tensiden für die Enhanced Oil Recovery. Dieser Übersichtsbeitrag behandelt Tenside, die zum chemischen Fluten verwendet werden, einschließlich TensidPolymer-Fluten und Alkali-Tensid-Polymer-Fluten. Im Gegensatz zu den meisten früheren Übersichtsbeiträgen auf diesem Gebiet konzentriert sich diese Übersicht auf die Tenside und nicht auf den Flutungsprozess. Sie befasst sich mit neueren Ergebnissen, hauptsächlich aus den Jahren 2010 und später. Bei Bedarf wird auf ältere Literatur verwiesen, um neuere Ergebnisse in eine Perspektive zu setzen.
\end{abstract}

Stichwörter: Enhanced oil recovery, Tensidflutung, Mikroemulsion, Winsor-System, Grenzflächenspannung

\section{Introduction}

Due to improved drilling techniques and to expectations of raising oil prices, there has been a renewed interest in enhanced oil recovery during the last decade. Many methods exist to increase the yield of oil beyond what can be achieved by just injecting water into the reservoir. They are collectively referred to as enhanced oil recovery (EOR) or tertiary oil recovery and they include chemical EOR, thermal EOR, hydrodynamic EOR and gas EOR. This review deals with one of the chemical EOR techniques: the use of surfactants to increase the recovery of oil from reservoirs. The surfactant, or surfactants, can be the sole chemical used for the purpose. However, in the majority of cases the surfactant is combined with some other chemical such as a polymer and/ or alkali. The use of a combination of surfactant and polymer is called surfactant-polymer (SP) flooding and the addi-

\footnotetext{
Research Institute of Petroleum Exploration \& Development, PetroChina, Beijing, China

Qingdao Institute of Bioenergy and Bioprocess Technology, Chinese Academy of Sciences, Qingdao, China

Shandong GiNZRE New Materials Development Co. Ltd., Jinan, China

University of Chinese Academy of Sciences, Beijing, China

University of Portsmouth, Portsmouth, UK

Chalmers University of Technology, Gothenburg, Sweden
}

tion of alkali, such as sodium hydroxide or calcium carbonate, gives alkali-surfactant-polymer (ASP) flooding.

One purpose of adding alkali is that the base generates salts of naphthenic acid from the oil, which means that a surface-active species is formed in situ. Simple inorganic salts, such as sodium carbonate, sodium bicarbonate or sodium hydroxide, are commonly used as alkali source but ammonia [1] and "organic alkali", such as ethanolamine [2], ethylene diamine [3] or polyoxypropylene diamine [4] offer advantages in reservoirs that contain gypsum, $\mathrm{CaSO}_{4}$. $2 \mathrm{H}_{2} \mathrm{O}$. Gypsum (and also anhydrite, $\mathrm{CaSO}_{4}$ ) precipitates as $\mathrm{CaCO}_{3}$ in the presence of carbonate ions. The use of sodium metaborate as alkali source is another way of circumventing the problem of precipitation in high salinity reservoirs since metaborate sequesters divalent cations $[5,6]$. It has been shown that for very acidic crude oils, i.e. those that contain a high proportion of naphthenic acids, the surfactant may be entirely replaced by alkali in combination with a cosolvent, such as isobutanol or propoxylated isobutanol [7]. Trials have also been made without any addition of alkali, i.e. SP flooding, see for instance Zhu et al. [8].

Thus, the use of surfactants for EOR goes under different headings such as chemical flooding, SP flooding or ASP flooding. Surface active agents can also be generated in situ by microorganisms injected into the reservoir. This procedure is usually referred to as Microbial Enhanced Oil Recovery (MEOR).

Surfactants are produced worldwide in large quantities and the applications range from household products such as food, personal care and detergents to heavy industrial processes such as mining, textile production and oil exploration. EOR is not any of the largest applications but the volume is growing. Surfactants are today mainly used for onshore operations in sandstone reservoirs but there is a potential also for off-shore fields. Carbonate reservoirs are less suitable for surfactant flooding. The positively charged rock surfaces of carbonate fields will cause massive loss of anionic surfactant due to adsorption. In addition, the high content of divalent cations in the formation water of carbonate fields may cause such surfactants to precipitate.

Surfactant flooding, usually either as SP or as ASP flooding, can be performed directly after the water flooding but it is common practice to first perform flooding with only polymer after cessation of the water flooding and start SP or ASP flooding when the oil cut in the polymer flooding has come down to a certain value. The role of the surfactant in the flooding operation is in principle the same regardless of the stage where it is injected.

This review deals with surfactants for surfactant flooding in a broad sense, including SP flooding and ASP flooding. Surfactants are also used for foam flooding but the action 
of the amphiphile is vastly different in this process than in surfactant flooding and foam flooding is outside the scope of this review. MEOR, which does not involve the addition of an external surfactant, is also not dealt with in the review.

EOR has a long history and a comprehensive book [9], as well as several good reviews, on surfactant flooding have been written through the years [10-16]. This review, unlike most of the previous reviews, has a surfactant focus, not a focus on the flooding process. It primarily deals with papers from 2010 and onwards but older references are also included to put the more recent literature into perspective.

\section{The role of the surfactant}

The main role of the surfactant used for EOR is to reduce the interfacial tension between the oil present in the reservoir and the injected water, $\gamma_{\mathrm{o} / \mathrm{w}}$. It has been known since long back that the amount of oil retained in the reservoir after water flooding will depend on the ratio between viscous forces striving to displace the oil and capillary forces, which trap the oil in the pores [17]. The relationship between the viscous and the capillary forces is often described by the capillary number, Nc, according to the expression

$$
\mathrm{Nc}=\eta v / \gamma_{\mathrm{o} / \mathrm{w}}
$$

Nc is a dimensionless number, $\eta$ is the viscosity and $v$ the viscosity, respectively, of the displacing fluid.

It has been found that the residual oil saturation in an oil reservoir is constant below a certain value of Nc, typically in the range $10^{-4}-10^{-5}$. Flooding with only water gives values of Nc below that number. Above a critical Nc value, however, the residual oil saturation after flooding decreases almost linearly with log Nc. Thus, the key to obtaining proper oil recovery is to attain a high enough value of Nc.

In principle, the Nc value can be raised by either increasing the viscous forces or decreasing the capillary forces. The viscous forces can be increased by thickening the water, e.g. by addition of a polymer, and/or by increasing the water pressure in the pumping. However, there is a limit to what can be done to the viscous forces. Too high viscosity or too high water pressure will damage the reservoir, generating cracks in the porous rock. The injected fluid will then go through the large cracks avoiding the narrow pores where most of the oil is situated.

Consequently, the approach taken to raise the Nc value is to drastically reduce the capillary forces (together with a moderate increase in the viscous forces using a polymer in the injection water). It has been demonstrated that, at least for water-wet reservoirs, a reduction of the oil-water interfacial tension down to $10^{-3} \mathrm{mN} \mathrm{m}^{-1}$ or even lower is needed to obtain proper mobilization of the oil in the reservoir [10].

An interfacial tension of the order of $10^{-3} \mathrm{mN} \mathrm{m}^{-1}$ is extremely small. The interfacial tension between an aliphatic hydrocarbon and water is around $50 \mathrm{mN} \mathrm{m}^{-1}$ and the interfacial tension between an aromatic hydrocarbon and water is typically $30 \mathrm{mN} \mathrm{m}^{-1}$. A surfactant monolayer at the oil-water interface reduces the interfacial tension to a few $\mathrm{mN} \mathrm{m}^{-1}$, still far from the interfacial tension value needed for EOR.

It was found during the early days of the development of surfactant flooding that if a surfactant or a surfactant system was chosen such that a microemulsion formed sponta- neously between the oil and the water phases, the two interfaces, the upper one between the excess oil phase and the microemulsion and the lower one between the microemulsion and the excess water phase, could have extremely low interfacial tension values. Under optimal conditions, when the surfactant is said to be balanced, the middle phase contains equal amounts of oil and water. Then the two interfacial tensions are approximately the same. Middle phase microemulsions were known since at least 1970 under the name 'surfactant phase' and Saito and Shinoda observed the exceptionally low interfacial tensions in such systems [18]. The internal structure of a middle phase microemulsion was later found to be bicontinuous, i.e. consisting of infinitely long and intertwined domains of oil and water with all interfaces covered by a monolayer of surfactant [19]. The choice of the surfactant (or surfactants) is critical. If the surfactant is too hydrophilic, then a two-phase system, an oil-in-water microemulsion in equilibrium with excess oil, a so-called Winsor I system, will form. If, on the other hand, the surfactant is too hydrophobic, another two-phase system, a water-in-oil microemulsion in equilibrium with excess water, will form, a Winsor II system. The interfacial tensions for these two-phase systems are low but not low enough to give proper mobilization of the oil in the reservoir. Only the balanced system with a bicontinuous microemulsion between the excess oil and water phases, a Winsor III system, gives the ultralow interfacial tension needed for the purpose. At that point, the surfactant is perfectly balanced, i.e. the packing parameter is close to 1 [20, 21]. Figure 1 shows the transition from a Winsor I, via a Winsor III to a Winsor II system together with typical values of interfacial tensions. The amphiphile is an anionic surfactant and the parameter used to induce the phase transitions is salinity. If instead the amphiphile had been a nonionic surfactant, then the temperature would have been the critical parameter, increasing the temperature leading to the Winsor $\mathrm{I} \rightarrow$ Winsor III $\rightarrow$ Winsor II transition. Figure 2 illustrates the structures of the different microemulsions. (The "Winsor" terminology originates from the British scientist P. A. Winsor, who described the phase behavior in a widely spread book [22]).

It is not only the salinity that affects the phase behavior for systems based on anionic surfactants, the concentration is also an important parameter. The surfactant is injected at a certain concentration but as the flooding progresses, the concentration will decrease due to dilution with reservoir water. The dilution will move the phase behavior in the direction Winsor I $\rightarrow$ Winsor III $\rightarrow$ Winsor II, i.e. from left to right in Figure 1. As will be discussed further down, this change in phase behavior can be compensated for using a so-called negative salinity gradient $[25,26]$.

It has been reported that an increase in pressure shifts the optimal salinity towards higher values [27]. Since it is challenging to perform phase behavior studies under high pressure, this means that the optimal formulation in the laboratory would have to be modified to fit the conditions of the field test. However, the effect of the pressure seems not to be large and is usually neglected in the development of formulations for surfactant flooding.

It was demonstrated already in the mid-1970s that there exists a relationship between the oil-water-surfactant phase behavior and the interfacial tensions in the system [28-30]. 
The term 'solubilization parameter' was coined for the amount of oil (or water) that a given amount of surfactant could solubilize in the middle phase. $\mathrm{S}_{\mathrm{o}}$ and $\mathrm{S}_{\mathrm{w}}$ represent the solubilization parameter for oil and water, respectively, and the system is balanced when $\mathrm{S}_{\mathrm{o}}=\mathrm{S}_{\mathrm{w}}$. Thus, a highly efficient surfactant (or surfactant system) gives high values of $\mathrm{S}_{\mathrm{o}}$ and $\mathrm{S}_{\mathrm{w}}$.
Somewhat later Huh showed that there is a reverse relationship between the interfacial tension and the solubilization parameter [31]. At optimal conditions, i. e. when there is equal solubilization of oil and water in the middle phase, then

$$
\mathrm{S}_{\mathrm{o}}=\mathrm{S}_{\mathrm{w}} \sim 1 / \gamma_{\mathrm{m} / \mathrm{w}}=1 / \gamma_{\mathrm{m} / \mathrm{o}}
$$

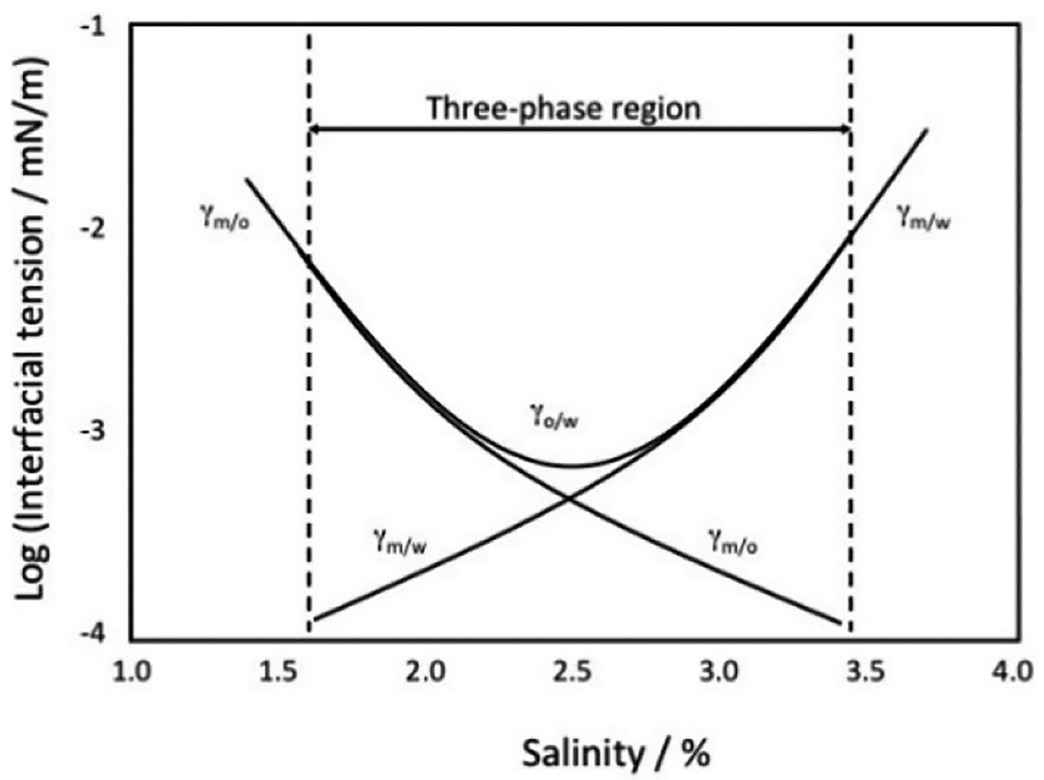

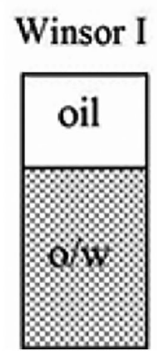
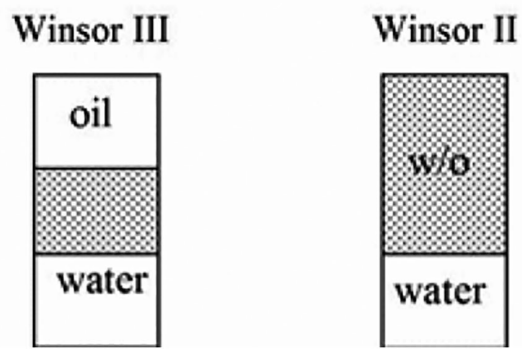

o/w microemulsion



positive curvature bicontinuous microemulsion

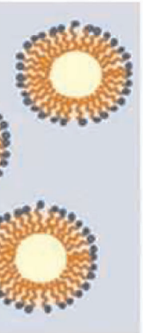

$33385^{\circ}$
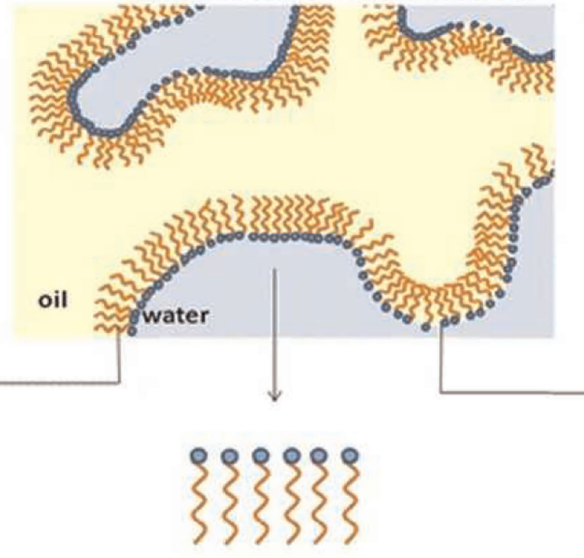

null curvature
Figure 1 A transition from Winsor I via Winsor III to Winsor II system can occur by increasing the salinity for a system based on oil, water and anionic surfactant. The interfacial tensions are also shown. As can be seen, the lowest interfacial tensions are obtained for the Winsor III system, where a microemulsion is in equilibrium with excess oil and water. The system is balanced at a salinity of $2.5 \%$. (Adapted from [23].)

Figure 2 Structure of left: an oil-in-water microemulsion; middle: a bicontinuous microemulsion; and right: a water-in-oil microemulsion. A monolayer of surfactant covers all oil-water interfaces. (Adapted from [24].) 
where $\gamma_{\mathrm{m} / \mathrm{w}}$ and $\gamma_{\mathrm{m} / \mathrm{o}}$ are the interfacial tensions between microemulsion and water and between microemulsion and oil, respectively in the Winsor III regime.

This means that instead of assessing surfactant efficiency by measuring the interfacial tensions, which can be relatively troublesome, one can get the solubilization parameters from the volumes of the three phases and then calculate the interfacial tension.

Another important role of the surfactant is to change the wetting characteristics of the reservoir. The wettability is a critical parameter for achieving proper mobilization of oil from a porous rock formation [32-34]. Most surfactants have the ability to improve wetting of water at the rock surface, which is essential. However, this is a general property of amphiphilic molecules and the surfactant need not be tailormade for the specific oil in the reservoir in order to provide good wetting. Thus, to change a poorly water-wet surface to a properly water-wet one is usually not as demanding a task as to obtain ultralow interfacial tension between the reservoir oil and the injection water.

Wettability alteration is particularly crucial for carbonate rocks, which are often oil-wet. It has been demonstrated that cationic surfactants such as decyltrimethylammonium bromide and its longer chain homologues are particularly effective for the purpose. The cationic surfactant seems to act by desorbing organic carboxylates from the rock surface by forming oil-soluble ion pairs and by incorporating them into micelles, generating mixed micelles of the cationic surfactant and amphiphilic carboxylates in the water phase [34, 35]. The proposed mechanism is illustrated in Figure 3.

Loss of surfactant during the flooding is a problem, not least from an economic perspective. Loss by adsorption is most important and will mainly depend on the character and composition of the formation. In general, pure sandstone rock will not adsorb anionic surfactants much since the rock surface is negatively charged. There are usually patches of clay and other minerals that act as adsorption sites for anionic surfactants. Clay embedded in the rock matrix has a negative charge on the faces and a positive charge on the edges, which means that the anionic surfactants will adsorb on the edges. The loss of anionic surfactant by adsorption in a sandstone reservoir is therefore correlated to the clay content of the rock.

An anionic surfactant present in the brine will give, if the surfactant concentration is high enough, either a bilayer or tightly packed micelles at the positively charged surface. Both structures will have surfactant headgroups facing the surface as well as the surrounding water [36]. Thus, the charge of the surface site will change from positive to negative. The adsorption is shown in Figure 4.

The anions that come with the alkali in ASP flooding, such as carbonate and bicarbonate ions, will also adsorb at these patches, thus reducing the surfactant loss. That is one, out of several, reasons to include alkali in the flooding formulation. The polymer used for SP or ASP flooding is also negatively charged and will compete for these sites as well.

Surfactant adsorption on carbonate rock is usually more severe than on sandstone but it has been demonstrated that adsorption of anionic surfactants on such surfaces can be substantially reduced if alkali is added in the formulation. Sodium carbonate seems to be particularly effective in this respect [38].

There is a plethora of papers in the literature dealing with adsorption of surfactants at different mineral surfaces. However, translating these results into adsorption at a carbonate

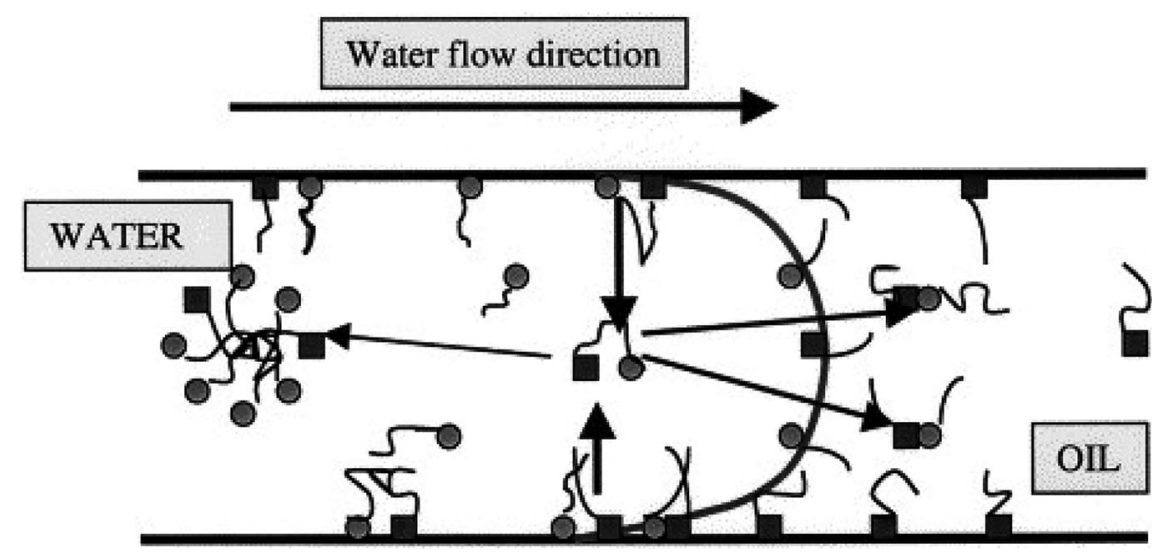

Figure 3 The suggested mechanism for the wettability alteration caused by cationic surfactants in a pore of carbonate rock. A circle with tail represents a cationic surfactant and a square with tail is an anionic amphiphile initially adsorbed at the surface and present in the oil. (Adapted from [34].)

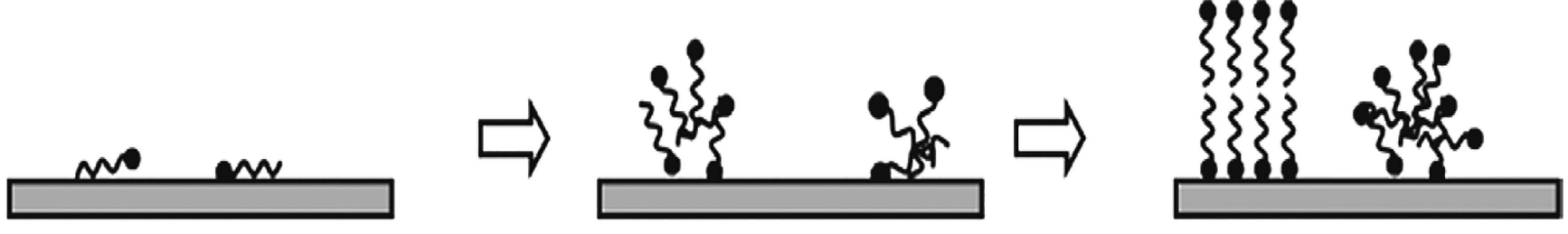

Figure 4 Adsorption of an anionic surfactant at a positively charged solid surface. At very low concentration individual molecules lie on the surface, attracted by electrostatic forces and hydrophobic interactions. At a certain concentration, the critical surface association concentration (CSAC), the surfactant will self-assemble into micelles at the surface. The CSAC is much lower than the critical micelle concentration (CMC) in the bulk water. With increasing bulk concentration, the surface will be progressively more covered either with micelles or with a surfactant bilayer. (From [37].) 
rock surface is not trivial. These surfaces are highly heterogeneous with respect to both mineralogy and surface chemistry. Besides the uncertainty regarding the solid surface, environmental parameters like ionic strength, $\mathrm{pH}$ and temperature will influence the adsorption. For instance, it has been shown that whereas adsorption of a cationic surfactant, cetylpyridium chloride, on synthetic calcite was negligible, the adsorbed amount on natural dolomite and limestone was considerable [39]. The content of aluminum and silicon in the natural carbonate was shown to be decisive. As pointed out by Tagavifar et al., more relevant results may be obtained if the adsorption study is carried out on model mineral surfaces with defined heterogeneity and with proper control of the environmental parameters [40]. They showed that anionic surfactants adsorb in a relatively high amount on a natural limestone up to a $\mathrm{pH}$ of 9 . Above $\mathrm{pH}$ 9 , as the surface becomes progressively more negative, the adsorbed amount decreases almost linearly with $\mathrm{pH}$.

As in most chemical engineering work, modeling goes hand in hand with the experimental work and both approaches are often needed to achieve good results. There are commercial simulators available today with capabilities for modeling and simulation of complex processes, such as chemical flooding. Modeling is, however, outside the scope of this review. Recent advances in modeling surfactant flooding can be found in [41-43].

\section{Types of surfactants used for chemical flooding}

The knowledge that interfacial tension reduction is a way to improve the recovery of oil from reservoirs is surprisingly old. Uren and Fahmy wrote in a paper from 1927: "A definite relationship exists between the interfacial tension of the oil against the flooding medium and the percentage recovery obtained by flooding. The efficiency of flooding increases as this interfacial tension decreases" [44]. The patent literature goes even further back [45]. In the work by Uren and Fahmy the interfacial tension reduction was obtained by the addition of inorganic salts. A large number of salts were tested, and the lowest interfacial tension and the best oil recovery were obtained with sodium carbonate. Thus, this is an early example of what is today called alkali flooding. The alkali added generated surface-active salts of naphthenic acids present in the crude.

The use of external surfactants for EOR appeared much later and in the early trials from the 1960s and 1970s lowcost petroleum sulfonates were mostly used. More systematic research to correlate oil recovery efficiency with surfactant structure started in the 1980s and the University of Texas at Austin was a focal point of this development. The work by Wade, Schechter, Pope and others at UT Austin together with researchers at Exxon, Shell and other oil companies demonstrated that excellent results could be obtained in core flooding experiments when the surfactant was tailormade for the specific reservoir oil, the composition of the brine used for flooding, the reservoir temperature, and other field- and oil-specific parameters [46, 47].

\subsection{One- or multicomponent systems}

Many industrial formulations of microemulsions are based on the use of one conventional surfactant together with a co- solvent, where the cosolvent is a small amphiphile, typically a medium chain alcohol. In fact, Schulman's pioneering work on microemulsions was formulated with an anionic surfactant and an alcohol. He noticed that a macroemulsion stabilized by a fatty acid salt became transparent after the addition of a cosolvent, such as a medium chain alcohol or amine [48]. Such microemulsions are relatively easy to prepare and attracted attention in the early days of surfactant flooding. However, it was soon realized that two such dissimilar amphiphiles as a large hydrophobic surfactant and a small and relatively hydrophilic alcohol would not stay together during the flooding process. One may expect an almost immediate phase separation in the column and the phase behavior obtained in the test tube would be lost. As a result, the surfactant-cosolvent route was not pursued.

From the point of view of maintaining the same phase behavior throughout the flooding process, a one surfactant formulation would be the best option. Then there would be no possibility for chromatographic separation of amphiphiles during the flooding and the phase behavior in the column would remain the same as in the test tube in the laboratory. However, optimizing the formulation with just one surfactant can be difficult since all other parameters, such as the character of the oil and the brine, temperature, etc, are fixed. The use of two surfactants, similar in character but slightly different on the hydrophilic-lipophilic scale is therefore advantageous. Two chemically similar surfactants will not undergo extensive chromatographic separation in the column (or in the reservoir) and the formulation can be optimized by varying the ratio between them.

\subsection{Anionic surfactants}

The majority of works on surfactant flooding have used one or more anionic surfactants in the formulation. They have been found to be excellent candidates for sandstone reservoirs, partly because of their low tendency to adsorb on the negatively charged rock surface.

Petroleum sulfonates have been popular since the start of using surfactants for EOR, the main reason being that they can be produced simply by sulfonation of a fraction of the crude in place using either concentrated sulfuric acid or oleum as sulfonating reagent [49-51]. The drawback of petroleum sulfonates is that they constitute a very heterogeneous mixture of surface-active molecules. Firstly, the character of the hydrophobic surfactant may vary considerably, e. g. because of differences in the degree of aromaticity of the crude. Secondly, the sulfonation will yield a mixture of species with a varying number of sulfonate groups, i.e. the surfactant will have more than one polar headgroup. Thirdly, the molecular weight distribution is broad. Thus, petroleum sulfonates are extremely undefined amphiphiles and a product from one producer may be very different from that from another. The petroleum sulfonate shown in Fig. 5 is just an example of how such a product may look.

Alkylbenzene sulfonates are a much better-defined type of sulfonate than the petroleum sulfonates and they are widely used in EOR formulations, often in combination with another anionic surfactant [52-53]. There are two main types of alkylbenzene sulfonates, those with a linear alkyl chain and those with a branched alkyl chain, usually a propene oligomer. The surfactants with a branched tail have been phased 
out from most applications because of low rate of biodegradation. They are still used to some extent in industrial applications where biodegradability is of minor importance, however. The molecule shown in Fig. 5 has a linear alkyl chain.

Alkylbenzene sulfonates have also been used in combination with a surface-active polymer, hydrophobically modified partially hydrolyzed polyacrylamide [54]. They are made by Friedel-Crafts alkylation of benzene followed by sulfonation, usually with $\mathrm{SO}_{3}$. The alkylation yields a mixture of isomers with the phenyl group attached to one of the non-terminal carbons of the alkyl chain. The sulfonation gives almost exclusively substitution in $p$-position. The character of alkylbenzene sulfonates can be adjusted by the choice of alkyl chain length. While C12 is most used in detergent formulations, longer chains, such as C16 or C18, are normally em- ployed in EOR formulations. The molecule shown in Fig. 5 is the C16 homologue, i. e. hexadecylbenzene sulfonate.

a-Olefin sulfonates are another type of sulfonate surfactant that has been used in flooding experiments [55, 56]. They are made by sulfonation of a long-chain $\alpha$-olefin and the product is a mixture of species, as shown in Fig. 5. Also internal olefin sulfonates have been used in formulations for surfactant flooding [38, 57-59] and also these surfactants are mixtures of alkene sulfonates and hydroxyalkane sulfonates, as can be seen from Fig. 5 .

Yet another class of sulfonate surfactants that has been explored for surfactant flooding are fatty acid methyl ester sulfonates [52, 60]. The structure is shown in Fig. 5.

All the sulfonate surfactants mentioned above are $\mathrm{pH}$ insensitive and they are resistant to hydrolysis, also at elevated

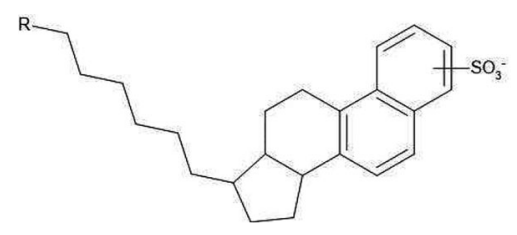

(a)<smiles>CCCCCCCCCCCCCCCCC(=O)O</smiles>

(c)<smiles>CCCCCCCCCCCCCCC(O)C(O)OC</smiles>

(e)

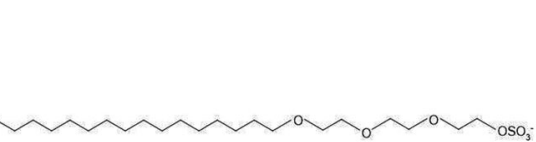

(g) (f)<smiles>[Al]C1CCCCC1</smiles>

(b)<smiles>CCCCC=CC(CCCCCCCCC)S(=O)(=O)[O-]</smiles><smiles>CCCCCCCCC(CCCC)COC(C)C(C)OS(C)(=O)=O</smiles>

(d)<smiles>CCCCCCCCCCCCCCCCOC(C)(O)OCCOCCC</smiles><smiles>CCCCCCCCCC(CC(O)CCCCCCCC)S(=O)(=O)[O-]</smiles>

(h)

$n=3-8$<smiles>CCCOCCOCC(=O)O</smiles>

(i)
Figure 5 Examples of anionic surfactants evaluated for surfactant flooding. a) petroleum sulfonate; b) linear alkylbenzene sulfonate; c) $\alpha$-olefin sulfonate ( $\alpha$-olefin sulfonates are typically mixtures of the alkene sulfonate and the 3-hydroxyalkane sulfonate shown in the figure; besides, there is a certain amount of the 4-hydroxyalkane sulfonate, not shown); d) internal olefin sulfonate (also a mixture of alkene sulfonate and hydroxyalkane sulfonate); e) fatty acid methyl ester sulfonate; f) sulfated straight-chain alcohol; g) sulfated oxyethylenated straight-chain alcohol (often called alcohol ether sulfate); $h$ ) sulfated oxypropylenated branched-chain alcohol; i) oxyethylenated straightchain alcohol carboxylate (often called alcohol ether carboxylate) 
temperatures. Fatty acid methyl ester sulfonates contain an ester linkage, but it is nevertheless very stable against hydrolysis because the sulfonate group adjacent to the ester bond prevents nucleophilic attack by hydroxyl ions at the carbonyl carbon.

Sulfates are closely related to sulfonates and sulfate-based surfactants are also frequently used in EOR formulations. They are sometime the sole surfactant in the formulation, but more often used in combination with another anionic surfactant, usually a hydrophobic alkylbenzene sulfonate. Compared to the sulfonates, sulfates suffer from one distinct disadvantage. They are not stable at temperatures above $60-70^{\circ} \mathrm{C}$. This limits their use to low temperature reservoirs and this limitation is valid also when the sulfate surfactant is used in combination with a sulfonate or some other hydrolytically stable amphiphile.

The simplest sulfate surfactants are sulfated fatty alcohols, made by reacting the fatty alcohol with $\mathrm{SO}_{3}$. Such surfactants are used in a variety of applications and the sodium salt of the C12 homologue, sodium dodecyl sulfate, or SDS, is one of the amphiphiles most frequently employed in surfactant-based formulations. Closely related to SDS are sulfates of ethoxylated fatty alcohols. Such surfactants are often referred to as alcohol ether sulfates or sulfated oxyethylenated alcohols. Dodecanol with two or three ethylene oxide (EO) units added and subsequently sulfated is widely used in dish-washing and personal care applications. Both sulfated fatty alcohols and sulfated oxyethylenated alcohols with EO inbetween the alkyl chain and the sulfate group have been investigated for surfactant flooding although the number of reports in the recent literature is relatively small [61-65]. The structures of the surfactants are given in Fig. 5. The work by Ji et al. is somewhat unusual in that they combined SDS with a surface-active polymer, hydrophobically modified and partially hydrolyzed polyacrylamide. Such a formulation has an intriguing rheological profile. The viscosity is governed by the ratio of surfactant to surface-active polymer, something that may be taken advantage of to increase the volumetric sweep efficiency.

While the traditional type of ether sulfate surfactants, i.e. those having EO in-between the alkyl chain and the sulfate group, have not been widely used in surfactant flooding experiments, the related class of surfactants having propylene oxide (PO) units instead of EO units in the molecule have been subject to considerable interest. Surfactants with a block of PO units in-between the hydrophobic tail and the polar headgroup have some interesting properties and such amphiphiles are sometimes called extended surfactants. As discussed in detail in a recent review by Salager et al., the polyoxypropylene block is hydrophobic but not as hydrophobic as the alkyl or alkylaryl chain that constitutes the surfactant tail [66]. Increasing the number of PO units in the molecule leads to a decrease of the critical micelle concentration [67], the cloud point [68] and the optimal salinity [69], all indicators of an increase in hydrophobicity. Adding two PO units has been found to correspond to one extra $\mathrm{CH}_{2}$ group in the alkyl chain. Since two PO units mean an increase of the chain length by six atoms, the use of PO as a middle segment in the surfactant is clearly a way to extend the length of the molecule without facing the problem of too strong intermolecular interaction that one often encounters with surfactants based on very long alkyl chains.
The effect of the PO units on the cloud point is particularly interesting. The cloud point phenomenon, which is well-known for nonionic surfactant of ethoxylated fatty alcohol type, is caused by a gradual loss of hydration water around the polyoxyethylene chain as the temperature is increased [70, 71]. At some point there is not enough hydration water left around the chain to keep the surfactant in solution. A separation into one surfactant-rich and one surfactant-poor phase occurs, which gives a cloudy appearance. The observation that also surfactants with a PO block in-between the alkyl chain and the polar headgroup exhibits a cloud point indicates that the phase behavior of the extended surfactants is temperature dependent. Increasing hydrophobicity with increasing temperature means that there will be a Winsor I > Winsor III > Winsor II transition as the temperature is raised. This temperature dependence can to some extent be compensated by mixing the extended surfactant with another sulfate or sulfonate surfactant that lacks the PO block. Such surfactants become slightly more hydrophilic with increasing temperature [72]. This is one of the reasons why mixtures of an extended surfactant and a regular anionic surfactant have become popular for EOR formulations.

Insertion of a PO or an EO block in-between the alkyl chain and the anionic headgroup improves the tolerance against divalent cations [69]. This effect is also seen in combination with another anionic surfactant.

The PO block in the extended surfactants will occupy the interfacial region in an oil-water system, and it strives to extend that interface, which is beneficial for obtaining a large middle-phase microemulsion in the system. Likely, the first PO units partition mostly into the oil while the PO units situated close to the polar headgroup partition into the water but the effect on the cloud point discussed above indicates that also those that reside on the oil side may be hydrated. The situation is illustrated in Fig. 6.

Extended sulfate surfactants may be of alcohol-PO- $\mathrm{SO}_{3}$ type but may also have the arrangement alcohol-PO-EO$\mathrm{SO}_{3}$ with sequential alkoxylation first with $\mathrm{PO}$, then with $\mathrm{EO}$, or alcohol-PO/EO-SO $\mathrm{S}_{3}$ where the alkoxylation is made with a mixture of PO and EO. The PO-EO mixture will not result in a completely random mixture, however, because EO is more reactive that PO. The number of PO units in sulfated oxppropylenated alcohols is typically 3-8. A drawback of surfactants containing PO blocks is that their biodegradability is slow. This limits their use since readily biodegradable surfactants are required for most applications. However, proper biodegradability is not a requirement for EOR surfactants (except in the North Sea) because the surfactant will eventually end up in the oil.

Surfactants with sulfate as polar headgroup are only useful for flooding in reservoirs that have a temperature of less than $70^{\circ} \mathrm{C}$. To circumvent this limitation, the corresponding surfactants with a sulfonate headgroup have been synthesized and evaluated [69]. These are glycidyl ether sulfonates of oxypropylenated alcohols. Their physical chemical properties are very similar to those of the corresponding sulfates but since the polar headgroup is bound to the PO block via a C-S bond, not via a C-O-S linkage, they are hydrolytically stable.

Extended surfactants have been intensively explored for EOR applications and particularly good results have been 
obtained when the surfactant is based on a branched hydrophobe. Guerbet alcohols, which have branching on the second carbon atom have been frequently used. A sulfated oxypropylenated surfactant based on a Guerbet alcohol is shown in Fig. 5. It has been found that branched surfactants in general give lower interfacial tension than surfactants with a linear alkyl chain with the same number of carbon atoms [21]. Such surfactants can be used as the sole amphiphile in a formulation for flooding $[74,75]$ but is it more common to combine the branched, extended sulfate surfactant with another anionic surfactant such as an alkylbenzene sulfonate, an $\alpha$-olefin sulfonate or an internal olefin sulfonate. Such mixtures have been found to give only negligible chromatographic separation of the surfactants, which is essential for maintaining the right phase behavior throughout the flooding process [76]. High yields were obtained in core flooding experiments when the ratio of the two surfactants was optimized and when a negative salinity gradient was used [77-79]. The negative salinity gradient $[25,26]$ was obtained by a stepwise decrease in alkali concentration in the sequence pre-water flush $>$ ASP slug $>$ polymer drive $>$ post-water flush. Also a combination of an internal olefin sulfonate with an extended sulfate surfactant gave good phase behavior and high oil recovery after flooding $[38,58]$.

Anionic surfactants can also be carboxylates with soap being the prime example. Carboxylates in general are more sensitive to hard water than sulfonates and sulfates and this limits their use in EOR. However, carboxylates are indirectly used in chemical flooding since the addition of alkali generates salts of naphthenic acids, which are carboxylate surfactants.

Insertion of EO units between the alkyl chain and the carboxylate group is a way to improve hard water tolerance of carboxylate surfactants [80] and the so-called oxpethylenated alcohol carboxplates, or alcohol ether carboxplates, have given promising results in surfactant flooding experiments [81]. In screening different surfactants for a high temperature, high salinity reservoir, an alcohol ether carboxylate turned out to be the best choice. Sulfate surfactants were too sensitive to hydrolysis and sulfonate surfactants precipitated as salt of divalent cations [82].

The anionic surfactants discussed above are all established on the market and can be obtained from producers all over the world. In the literature there are also examples of anionic surfactants synthesized in the laboratory and evaluated for surfactant flooding. One example is a gemini type of alkylaryl sulfonate, i.e. a surfactant with two hydrophobic tails and two polar headgroups [51]. Another type of anionic gemini surfactant, consisting of two long-chain alkyl sulfonate moieties connected by an aromatic ring was developed by Salehi et al. and gave promising results in core flooding experiments [61].

Liyanage et al. synthesized a large, hydrophobic ether sulfate surfactant based on tristyrylphenyl as hydrophobe. The hydrophobe was propoxylated and ethoxylated and finally sulfated. The phase behavior, as well as results from core flooding experiments, was encouraging [83].

Yet another unusual anionic surfactant tested in surfactant flooding experiments is surfactin, a biosurfactant produced by Bacillus subtilis [61]. Surfactin is a lipopeptide that carries two carboxylate groups in its polar part. However, neither surfactin, nor saponin [84] or other amphiphiles made by fermentation are realistic candidates for large scale flooding due to economic reasons.

Kumar et al. have synthesized a polymeric anionic surfactant and evaluated it for enhanced oil recovery [85]. Polymeric surfactants have the potential to combine in one molecule the rheological effect exerted by the polymer with the interfacial tension reduction caused by the surfactant [86]. However, polymeric surfactants are generally not good at creating Winsor III systems. Low molecular weight amphiphiles are more efficient in that respect. Even larger amphiphilic species than polymers have been suggested for surfactant flooding. For instance, Hamdi et al. synthesized graphene nanoplatelets grafted with the natural polymer gum Arabic [87]. Such species are also unlikely to generate Winsor III systems, however.

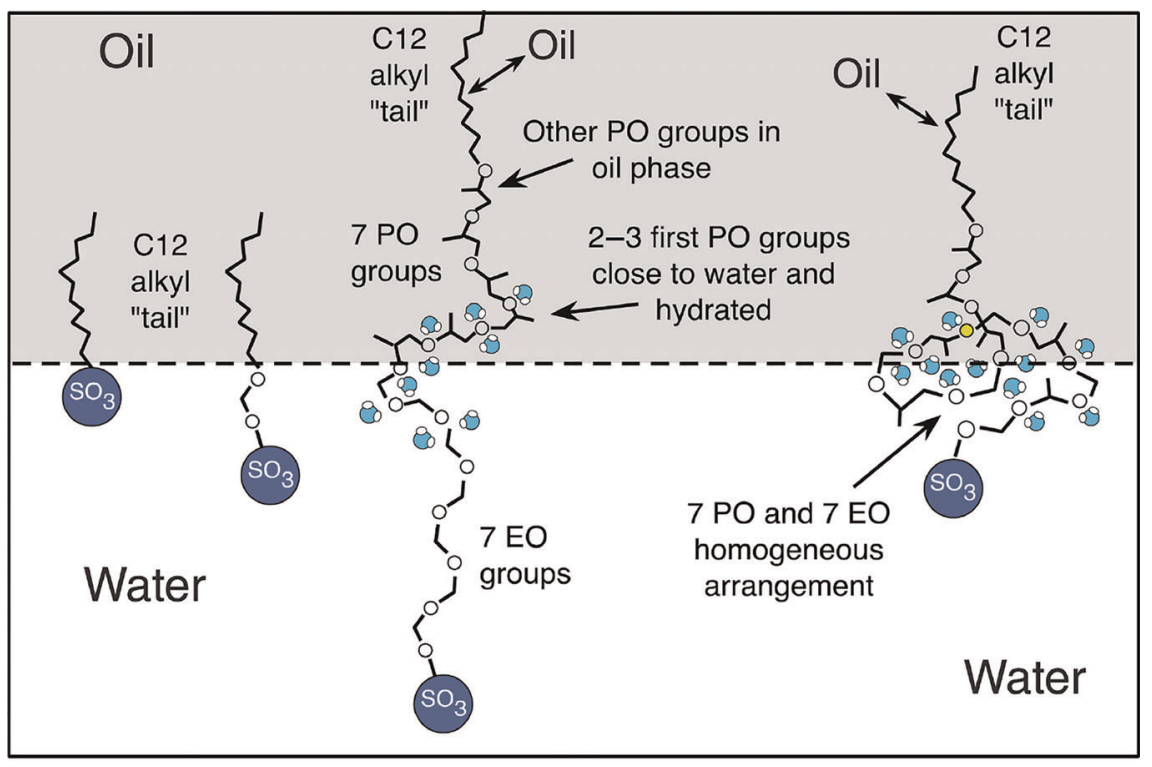

Figure 6 Position of sulfate-based surfactants at the oil-water interface. From left to right: a sulfated straight-chain alcohol, a sulfated oxyethylenated straight-chain alcohol with two EO units, a sulfated oxypropylenated and oxyethylenated straightchain alcohol with seven PO units and seven EO units added in sequence, a sulfated oxypropylenated and oxyethylenated branched-chain alcoho with seven PO units and seven EO units added together. (From [73].) 


\subsection{Cationic surfactants}

Cationic surfactants as the sole amphiphile are not considered candidates for flooding in sandstone reservoirs although the literature contains a couple of examples of cationic gemini surfactants being used in such experiments $[88,89]$. Cationic amphiphiles have a strong tendency to adsorb on the negatively charged surfaces of sandstone rock and the losses due to adsorption would be excessive.

The situation is different for carbonate reservoirs, where a change from primarily oil-wet to primarily water-wet is crucial, more so than for sandstone reservoirs, which are often water-wet from the beginning. Cationic surfactants have been shown to be effective in achieving wettability alteration of carbonate rock [90] but even better results appear to be obtained by mixtures of cationic and nonionic surfactants [91]. The cationic surfactants explored for wettability alteration are of the type long-chain alkyltrimethyl ammonium bromide (or chloride), see Fig. 7(a).

\subsection{Mixtures of anionic and cationic surfactants}

Mixtures of anionic and cationic surfactants are widely used in surfactant-based formulations. Such mixtures can be very surface-active with values of critical micelle concentration two orders of magnitude lower than those of the individual surfactants $[92,93]$. This means that the formation of mixed monolayers at interfaces, both solid-liquid, liquid-liquid and liquid-gas, is favored. In both the mixed micelles and the mixed monolayers the surfactants align with alternating anionic and cationic species. The favorable entropy originates from the fact that such mixed assemblies bring no counterions along; thus, there is no counterion entropy involved in the self-assembly, just as for nonionic surfactants.

A one-to-one molar mixture of an anionic and a cationic surfactant is sometimes called a catanionic surfactant and these have been thoroughly treated in the literature [94]. In mixing the two surfactants there is a limit with respect to chain length, however. For straight chain anionic and cationic surfactants the limit lies at twelve carbon atoms in the chains. For C12 and below mixed micelles form in solution but beyond that chain length the mixture usually precipitates.

Zhang et al. have investigated mixtures of the cationic surfactant benzalkonium chloride (alkyldimethylbenzyl ammonium chloride) (see Fig. 7(b)) and three different anionic surfactants: alkylbenzene sulfonate, alcohol ether sulfate

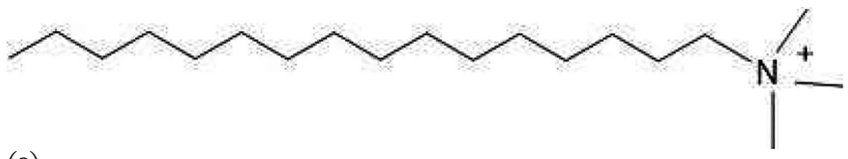

(a)

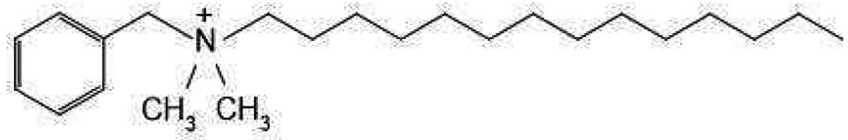

(b)

Figure 7 Examples of cationic surfactants evaluated for surfactant flooding. a) Cetyltrimethylammonium; b) benzalkonium (alkyldimethylbenzyl) and fatty acid methyl ester sulfonate (see Fig. 5) [52]. The mixing ratio of the two surfactants turned out to be critical but at the optimum ratio Winsor III systems were obtained with large solubilization parameters, i.e. very low oil-water interfacial tensions. Li et al. investigated formulations based on an oxyethylenated nonylphenol carboxylate together with long-chain alkyltrimethyl ammonium surfactants. They found that the synergy observed for the mixtures of anionic and cationic surfactants could be taken advantage of for surfactant flooding. They also found that a slight excess of anionic surfactant in the mixture was advantageous $[81,95]$.

\subsection{Zwitterionic surfactants}

Zwitterionic surfactants carry both a positive and a negative charge, which means that they have a net zero charge; thus, they are sometimes included in the nonionic surfactant class. However, the charges need not be permanent. If the positive charge comes from a quaternary ammonium group, then it is permanent but if it emanates from a protonated amine, then it will gradually lose its charge with increasing $\mathrm{pH}$. Likewise, while a sulfonate as the anionic group will always be negatively charged, a carboxylate group will gradually lose its negative charge with decreasing $\mathrm{pH}$. Thus, a zwitterionic surfactant based on a protonated amine and a carboxylate group as the positive and negative charges, respectively, will go from being a cationic surfactant at low $\mathrm{pH}$ to a nonionic surfactant at intermediate $\mathrm{pH}$ and an anionic surfactant at high $\mathrm{pH}$. Such amphiphiles are called amphoteric surfactants.

Zwitterionic surfactants have been tested for surfactant flooding, either as the sole surfactant or, more commonly, in combination with an anionic surfactant. Wang et al. [96], as well as Kumar and Mandal [97], reported good phase behavior and promising flooding and imbibition results with betaine surfactants, an example of a zwitterionic surfactant with a permanent positive charge but with a non-permanent negative charge. Figure 8 shows the structure of betaine surfactants. A series of zwitterionic gemini surfactants based on quaternary ammonium and phosphate as positive and negative functional groups, respectively, has also been synthesized and evaluated for surfactant flooding [98].

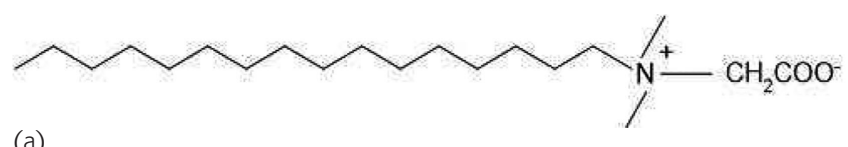

(a)

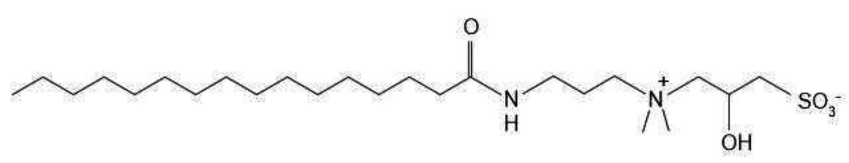

(b)

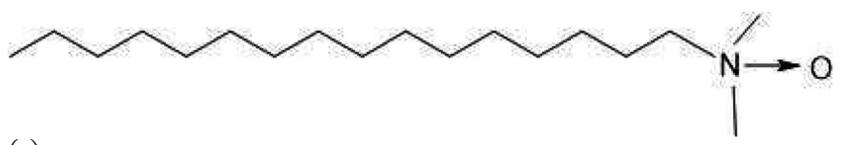

(c)

Figure 8 Examples of zwitterionic surfactants evaluated for surfactant flooding. a) Betaine; b) cocoamidopropyl hydroxysultaine; c) amine oxide 


\subsection{Mixtures of anionic and zwitterionic surfactants}

In three recent papers from the same group the zwitterionic surfactant cocoamidopropyl hydroxysultaine (see Fig. 8) was used together with either a sulfated oxypropylenated branched-chain alcohol or an alkylbenzene sulfonate (see Fig. 5) [56, 79, 99]. As can be seen from Fig. 8, cocoamidopropyl hydroxysultaine is an example of a zwitterionic surfactant with permanent charges. Particularly promising results were obtained with mixtures of cocoamidopropyl hydroxysultaine and a sulfated oxypropylenated C16-17 alcohol. The interfacial tension values at the optimum ratio of the surfactants were very low and the oil recovery after core flooding was high.

Amine oxide surfactants are examples of zwitterionic surfactants that are amphoteric, i.e. amphiphiles that can go from being cationic, via net nonionic to anionic as the $\mathrm{pH}$ is raised from low to high. A long-chain alkyldimethyl amine oxide surfactant, see Fig. 8, was used together with an anionic surfactant, a sulfated oxyethylenated alcohol (see Fig. 5) [52]. Such a mixture is interesting because the amine oxide surfactant will take up a proton and become positively charged as soon as it meets the anionic surfactant in solution. This will occur also at neutral $\mathrm{pH}$ when the amine oxide amphiphile is otherwise non-charged and the driving force for the protonization is the entropically favorable formation of mixed micelles (and mixed monolayers at the oilwater interface) composed of species with matching charges, as was discussed above for mixtures of anionic and cationic surfactants. The situation is shown in Fig. 9.

In a more recent work, the same amine oxide surfactant was combined with a sulfated oxypropylenated alcohol (see Fig. 5), yielding an appropriate phase behavior with very low interfacial tension values [99].

\subsection{Mixtures of nonionic and anionic surfactants}

Nonionic surfactants have either a polyoxyethylene chain or a polyol as polar headgroup and Fig. 10 shows examples of the two classes. The polyol may be glucose or some other sugar and it may also be glycerol or a glycerol oligomer. Since nonionic surfactants do not have counterions, their self-assembly, in bulk and at surfaces, occurs much more readily than for anionic and cationic surfactants. The critical micelle concentration for a nonionic surfactant is around two orders of magnitude lower than for a charged surfactant with equal number of carbon atoms in the hydrophobic chain. Thus, nonionic surfactants (as well as zwitterionic surfactants) are more efficient than anionics and cationics [100].
Despite their high efficiency, nonionic surfactants have not been much used in surfactant flooding experiments. There are only few reports of nonionics being explored as the sole surfactant $[101,102]$. One reason for the low interest in nonionic surfactants is that they adsorb heavily at most surfaces, which means that losses due to adsorption at rock surfaces will be substantial.

Nonionics have more often been tested for surfactant flooding in combination with an anionic surfactant, however, and such mixtures have been claimed to exhibit good salt tolerance [9]. Ding et al. and Hongyan et al. used alkoxylated fatty alcohols together with sulfonate surfactants and tested the mixtures in SP flooding $[49,103]$. Addition of the nonionic surfactant to a formulation based on a petroleum sulfonate (see Fig. 5) was found to improve the interfacial activity and to give better flooding efficiency [49].

Also, sugar-based nonionic surfactants have been explored either as the sole surfactant [104] or in combination with an anionic surfactant [82]. An alkylglucoside surfactant was found to improve the performance of a formulation based on the anionic surfactant alcohol ether carboxylate (see Fig. 5).

\subsection{Use of a cosolvent}

A cosolvent is a small molecule, often an alcohol in the C3C5 range or a short-chain glycol ether that is added to the surfactant formulation in order to improve the surfactant solubility, which is important for keeping control of surfactant retention during the flooding [105]. The cosolvent may also prevent the formation of lamellar liquid crystals, which can be detrimental to the flooding process. Cosolvents are useful in laboratory work because they promote rapid equilibration.

Many formulations that have been used for surfactant flooding contain a cosolvent, but it is important to keep the

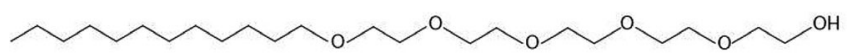

(a)

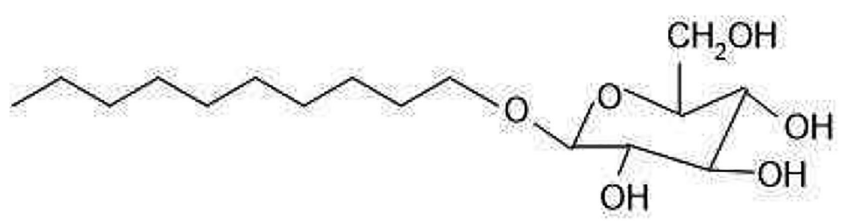

(b)

Figure 10 Examples of nonionic surfactants evaluated for surfactant flooding. a) Fatty alcohol ethoxylate; b) alkyl glucoside
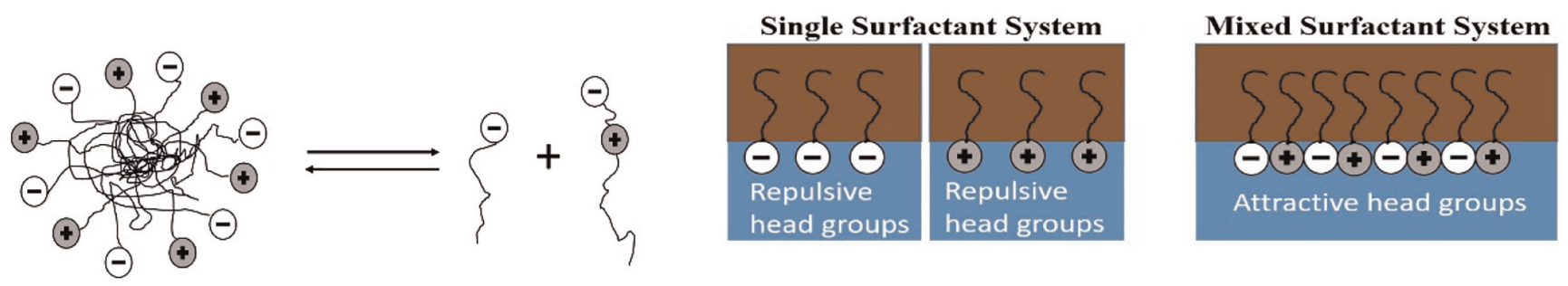

Figure 9 Left: a mixed micelle of an amine oxide surfactant, in protonated form, and a sulfated oxyethylenated alcohol. The micelle is in equilibrium with the unimers, and as free unimer in solution the amine oxide reverts to a zwitterionic surfactant. Right: A mixed monolayer at the oil-water interface gives a much tighter packing than monolayers of either anionic or cationic surfactants 
amount low. The cosolvent will typically decrease the magnitude of the solubilization parameters [79], i.e. the interfacial tensions in the Winsor III system will increase according to Huh's relationship discussed above. In addition, since the cosolvent is usually more hydrophilic than the surfactants used for flooding, the optimal salinity will be shifted towards higher values. Branched alcohols are more hydrophilic than their linear isomers; thus, isobutanol induces a slightly larger shift in optimal salinity than $n$-butanol.

\section{Conclusions}

In this review we have shown that all four major classes of surfactants, i.e. anionics, nonionics, cationics, and zwitterionics, have been explored for surfactant flooding. However, anionic surfactants dominate, the main reason being that they do not adsorb strongly on the negatively charged surfaces of sandstone reservoirs. Both sulfate and sulfonate surfactants have been widely used but sulfates are hydrolytically unstable and can only be used in fields with a reservoir temperature below $70^{\circ} \mathrm{C}$.

The formulations may be based on one amphiphile but it is more common to use a combination of two surfactants. If the two surfactants are similar in character, particularly with respect to headgroup charge and degree of hydrophobicity, then they can be expected to stay together during the flooding process, i.e., there will be only little chromatographic separation, which is a requirement for successful flooding.

In recent years there has been a strong interest in the use of so-called extended surfactants. An extended surfactant is an amphiphile that contains a PO block in-between the hydrophobic tail and the polar headgroup [66]. The PO block adds hydrophobicity to the amphiphile, and it will mainly be situated on the oil side of the oil-water interface. More importantly, it increases the length of the hydrophobic part of the molecule, i.e. the surfactant reaches further into the oil domain, which seems to be advantageous for achieving very low interfacial tension. Such surfactants have proven efficient in generating Winsor III phase behavior with a large middle phase microemulsion. They are also more tolerant to divalent cations than the corresponding surfactants without the PO block.

Cationic surfactants alone are not of interest for flooding in sandstone reservoirs because there would be an extensive loss of surfactant due to adsorption at the rock surface. They are of some interest for flooding in limestone reservoirs, however, where they can transform surfaces from oil-wet to water-wet. An interesting approach is to use mixtures of cationic and anionic surfactants for flooding. Such mixtures, sometimes called catanionic surfactants, can be extremely surface active with a critical micelle concentration two orders of magnitude lower than the values for the individual surfactants. It has been found that a slight excess of the anionic surfactant in such a mixture can be advantageous [95].

Also, combinations of zwitterionic and anionic surfactants have given promising results with respect to phase behavior and flooding efficiency. Two types of zwitterionic surfactants have proven to be of interest, those with permanent charges and those that in the presence of an anionic surfactant will take up a proton and become positively charged. Cocoamidopropyl hydroxysultaine is an example of a zwitterionic amphiphile with permanent charges and surfactants with betaine as headgroup as well as long-chain amine oxides are examples of amphiphiles that can become cationic. Mixtures of such zwitterionic surfactants and a sulfate- or a sulfonate-based surfactant can be very efficient in generating Winsor III phase behavior with extremely low interfacial tension values [52, 56, 99, 79].

\section{Acknowledgements}

This work was supported by the Shandong Key Research and Development Program (2019JZZY010349)

\section{References}

1. Sharma, H., Weerasooriya, U., Pope, G. A. and Mohanty, K. K: Ammonia-based ASP floods in carbonate cores containing gypsum, Fuel 184 (2016) 362-370. DOI:10.1016/j.fuel.2016.07.014

2. Fu, L., Zhang, G., Ge, J., Liao, K., Pei, H., Jiang, P. and Li, X.: Study on organic alkali-surfactant-polymer flooding for enhanced ordinary heavy oil recovery, Colloids Surfaces A 508 (2016) 230-239. DOI:10.1016/j.colsurfa.2016.08.042

3. Chen, Z., Zhao, X., Wang, Z. and Fu, M. A.: comparative study of inorganic alkaline/polymer flooding and organic alkaline/polymer flooding for enhanced heavy oil recovery, Colloids Surfaces A 469 (2015) 150- 157. DOl:10.1016/j.colsurfa.2015.01.008

4. Wang, Z., Hu, R., Ren, G., Li, G., Liu, S., Xu, Z. and Sun, D.: Polyetheramine as an alternative alkali for alkali/surfactant/polymer flooding, Colloids Surfaces A 581 (2019) 123820. DOI:10.1016/j.colsurfa.2019.123820

5. Flaaten, A. K., Nguyen, Q. P., Zhang, J., Mohammadi, H. and Pope G. A.: Alkaline/surfactant/polymer chemical flooding without the need for soft water, SPE J. 15 (2010) 184- 196. DOI:10.2118/116754-PA

6. Chen, F., Jiang, H., Bai, X. and Zheng, W.: Evaluation the performance of sodium metaborate as a novel alkali in alkali/surfactant/polymer flooding, J. Industr. Engin. Chem. 19 (2013) 450-457. DOI:10.1016/j.jiec.2012.08.029

7. Sharma, H., Panthi, K. and Mohanty, K. K.: Surfactant-less alkali-cosolventpolymer floods for an acidic crude oil, Fuel 215 (2018) 484-491. DOI:10.1016/j.fuel.2017.11.079

8. Zhu, Y., Zhang, Y., Niu, J., Liu, W. and Hou, Q.: The research progress in the alkali-free surfactant-polymer combination flooding technique, Petroleum Exploration Develop. 39 (2012) $371-376$. DOl:10.1016/S1876-3804(12)60053-6

9. Sheng, J. J.: Modern Chemical Enhanced Oil Recovery: Theory and Practice, Gulf Professional Publ., Kidlington, UK (2010);. DOI:10.1016/C2009-0-20241-8

10. Hirasaki, G. J., Miller, C. A. and Puerto, M.: Recent advances in surfactant EOR, SPE J. 16 (2011) 889-907. DOI:10.2118/115386-PA

11. Mwangi, P. M. and Rao, D. N.: An overview of surfactants in enhanced oil recovery, in Romsted, L. S. (Ed.), Surfactant Science and Technology, CRC Press, Boca Raton, FL (2014) 489-505. DOl:10.1201/b16802

12. Olajire, A. A.: Review of ASP EOR (alkaline surfactant polymer enhanced oil recovery) technology in the petroleum industry: Prospects and challenges, Energy 77 (2014) 963-982. DOI:10.1016/j.energy.2014.09.005

13. Sheng, J. J.: A comprehensive review of alkaline-surfactant-polymer (ASP) flooding. Asia-Pacific J. Chem. Engin. 9 (2014) 471 - 489. DOI: 10.1002 /apj.1824

14. Sheng, J. J.: Status of surfactant EOR technology, Petroleum 1 (2015) 97- 105. DOI:10.1016/j.petlm.2015.07.003

15. Kamal, M. S., Hussein, I. A. and Sultan, A. S.: Review on surfactant flooding: Phase behavior, retention, IFT, and field applications, Energy Fuels 31 (2017) 7701 - 7720. DOI:10.1021/acs.energyfuels.7b00353

16. Pal, N., Saxena, N. and Mandal, A.: Characterization of alkali-surfactant-polymer slugs using synthesized gemini surfactant for potential application in enhanced oil recovery, J. Petroleum Sci. Engin. 168 (2018) 283-300. DOl:10.1016/j.petrol.2018.05.026

17. Taber, J. J.: Dynamic and static forces required to remove a discontinuous oil phase from porous media containing both oil and water, SPE J. 9 (1969) 3- 12. DOI: 10.2118/2098-PA

18. Saito, $H$. and Shinoda, $K$.: The stability of w/o type emulsions as a function of temperature and of the hydrophilic chain length of the emulsifier, J. Colloid Interface Sci. 32 (1970) 647-651;. DOI:10.1016/0021-9797(70)90158-X

19. Scriven, L. E.: Equilibrium bicontinuous structure, Nature 263 (1976) $123-125$. DOI: 10.1038/263123a0

20. Nagarajan, R.: Molecular packing parameter and surfactant self-assembly: The neglected role of the surfactant tail, Langmuir 18 (2002) 31 - 38 DOl: 10.1021/la010831y

21. Rosen, M. J., Wang, H., Shen, P. and Zhu, Y.: Ultralow interfacial tension for enhanced oil recovery at very low surfactant concentrations, Langmuir 21 (2005) 3749-3756. DOl:10.1021/la0400959

22. Winsor, P. A.: Solvent Properties of Amphiphilic Compounds, Butterworth, London, UK (1954). DOI:10.1002/lipi.19560581222 
23. Kronberg, B., Holmberg, K. and Lindman, B.: Surface Chemistry of Surfactants and Polymers, Wiley, Chichester, UK (2014) 463.

DOI:10.1002/9781118695968

24.Santana, R. C., Perrechil, F. A. and Cunha, R. L.: High- and low-energy emulsification for food applications: A focus on process parameters, Food Engin. Rev. 5 (2013) 107 - 122. DOI: 10.1007/s12393-013-9065-4

25. Nelson, R. C. and Pope, G. A.: Phase relationships in chemical flooding, SPE J. 18 (1978) 325-338. DOI:10.2118/6773-PA

26. Nelson, R. C.: Further studies on phase relations in chemical flooding, in Shah, D. O. (Ed.), Surface Phenomena in Enhanced Oil Recovery, Plenum Publ., New York, NY (1981) 73 - 104. DOI:10.1007/978-1-4757-0337-5

27. Skauge, A. and Fotland, P.: Effect of pressure and temperature on the phase behavior of microemulsions, SPE Reservoir Engin. 5 (1990) $601-608$. DOI:10.2118/14932-PA

28. Healy, R. N. and Reed, R. L.: Physicochemical aspects of microemulsion flooding, SPE J. 14 (1974) 491 - 501. DOI: 10.2118/4583-MS

29. Healy, R. N., Reed, R. L. and Stenmark, D. K.: Multiple microemulsion systems, SPE J., 16 (1976) 147- 160. DOI:10.2118/5565-PA

30. Read, R. L. and Healy, R. N.: Some physico-chemical aspects of microemulsion flooding: a review, in Shah, D. O and Schechter, R. S. (Eds.), Improved Oil Recovery by Surfactant and Polymer Flooding, Academic Press, New York, NY (1977) 383-437. DOI:10.1016/B978-0-126-41750-0.X5001-4

31. Huh, C.: Interfacial tensions and solubilizing ability of a microemulsion phase that coexists with oil and brine, J. Colloid Interface Sci. 71 (1979) 408-426. DOI:10.1016/0021-9797(79)90249-2

32. Ayirala, S. C., Vijapurapu, C. S. and Rao, D. N.: Beneficial effects of wettability altering surfactants in oil-wet fractured reservoirs, J. Petroleum Sci. Engin. 52 (2006) 261 - 274. DOI:10.1016/j.petrol.2006.03.019

33. Babadagli, T:: Analysis of oil recovery by spontaneous imbibition of surfactant solution. Oil \& Gas Sci. Technol. 60 (2005) 697-710. DOI:10.2516/ogst:2005049

34. Standnes, D. C. and Austad, T: Wettability alteration in chalk: 2. Mechanism for wettability alteration from oil-wet to water-wet using surfactants, J. Petroleum Sci. Engin. 28 (2000) 123-143. DOI:10.1016/S0920-4105(00)00084-X

35. Jarrahian, K., Seiedi, O., Sheykhan, M., Vafaie Sefti, M. and Ayatollahi, S. Wettabiliy alteration of carbonate rocks by surfactants: A mechanistic study, Colloids Surfaces A 410 (2012) 1 - 10. DOI:10.1016/j.colsurfa.2012.06.007

36. Kronberg, B., Holmberg, K. and Lindman, B.: Surface Chemistry of Surfactants and Polymers, Wiley, Chichester, UK (2014) 159- 160. DOI: 10.1002/9781118695968

37. Holmberg, K.: Surfactants, in Ullmann's Encyclopedia of Industrial Chemistry, Wiley-VCH, Weinheim, Germany (2019) 14. DOI:10.1002/14356007.a25_747.pub2

38. Liu, S., Zhang, D. L., Yan, W., Puerto, M., Hirasaki, G. J. and Miller, C. A.: Favorable attributes of alkaline-surfactant-polymer flooding, SPE J. 13 (2008) 5- 16. DOI: 10.2118/99744-PA

39. Ma, K., Cui, L., Dong, Y., Wang, T., Da, C., Hirasaki, G. J. and Biswal, S. B.: Adsorption of cationic and anionic surfactants on natural and synthetic carbonate materials, J. Colloid Interface Sci. 408 (2013) 164- 172 DOI: 10.1016/j.jcis.2013.07.006

40.Tagavifar, M., Jang, S. H., Sharma, H., Wang, D., Chang, L. Y., Mohanty, K. and Pope, G. A.: Effect of $\mathrm{pH}$ on adsorption of anionic surfactants on limestone: Experimental study and surface complexation modeling, Colloids Surfaces A 538 (2018) 549-558. DOI:10.1016/j.colsurfa.2017.11.050

41. Dang, C., Nghiem, L., Nguyen, N., Yang, C., Chen, Z. and Bae, W.: Modeling and optimization of alkaline-surfactant-polymer flooding and hybrid enhanced oil recovery processes, J. Petroleum Sci. Engin. 169 (2018) 578-601. DOI:10.1016/i.petrol.2018.06.017

42.Druetta, P. and Pichioni, F.: Surfactant flooding: The influence of the physical properties on the recovery efficiency, Petroleum 6 (2020) 149- 162. DOl:10.1016/j.petlm.2019.07.001

43. Kumar, A and Mandal, A.: Core-scale modelling and numerical simulation of zwitterionic surfactant flooding: Designing of chemical slug for enhanced oil recovery, J. Petroleum Sci. Technol. 192 (2020) 107333. DOI:10.1016/j.petrol.2020.107333

44. Uren, L. C. and Fahmy, E. H.: Factors influencing the recovery of petroleum from unconsolidated sands by waterflooding, Trans. AIME 77 (1927) 318-335. DOI: 10.2118/927318-G

45. Squires, F.: Method of recovering oil and gas, U. S. Patent No. 1238355 (1917).

46. Abe, M., Schechter D., Schechter R. S., Wade, W. H., Weerasooriya, U. and Yiv, $S$ : Microemulsion formation with branched tail polyethylene sulfonate surfactants, J. Colloid Interface Sci. 114 (1986) 342-356. DOI:10.1016/0021-9797(86)90420-0

47. Bourrel, M. and Schechter R. S.: Microemulsions and Related systems: Formulations, Solvency and Physical Properties. Surfactant Science Series, Vol. 30, Marcel Dekker, New York, NY, (1988); DOI: 10.1080/01932699008943264

48. Hoar, T. P. and Schulman, J. H.: Transparent water-in-oil dispersions: The oleopathic hydro-micelle, Nature 152 (1943) 102-103. DOI:10.1038/152102a0

49. Hongyuan, W., Xulong, C., Jichao, Z. and Aimei, Z.: Development and application of dilute surfactant-polymer flooding system for Shengli oilfield, J. Petroleum Sci. Engin. 65 (2009) 45-50. DOl:10.1016/j.petrol.2008.12.021

50. Negin, C., Ali, S. and Xie, Q.: Most common surfactants employed in chemical enhanced oil recovery, Petroleum 3 (2017) 197-211. DOI: 10.1016/j.petlm.2016.11.007
51. Wang, Y., Liu, H., Wang, J., Dong, $X$. and Chen, F.: Formulation development and visualized investigation of temperature-resistant and salt-tolerant surfactant-polymer flooding to enhance oil recovery, J. Petroleum Sci. Engin. 174 (2019) 584-598. DOI:10.1016/j.petrol.2018.11.074

52.Zhang, G., Yu, J., Du, C. and Lee, R.: Formulation of surfactants for very low/ high salinity surfactant flooding without alkali, Proceedings of the SPE International Symposium on Oilfield Chemistry, The Woodlands, TX, April 13-15, 2015. DOI: $10.2118 / 173738-M S$

53. Riswati, S. S., Bae, W., Park, C., Permadi, A. K. and Efriza, I.: Experimental ananlysis to design optimum phase type and salinity gradient of alkaline surfactant polymer flooding at low saline reservoir, J. Petroleum Sci. Engin. 173 (2019) 1005 - 1019. DOI: 10.1016/j.petrol.2018.09.087

54. Feng, R.-S., Guo, Y.-J., Zhang, X.-M., Hu, J. and Li, H.-B.: Alkali/surfactant/polymer flooding in the Daqing oilfield class II reservoirs using associating polymer. J. Chem. (2013) 1 -6. DOl:10.1155/2013/275943

55. Yuan, C.-D., Pu, W.-F., W, X.-C., Sun, L., Zhang, Y.-C. and Cheng, S.: Effects of interfacial tension, emulsification, and surfactant concentration on oil recovery in surfactant flooding process for high temperature and high salinity reservoirs, Energy \& Fuels 29 (2015) 6165-6176. DOl:10.1021/acs.energyfuels.5b01393

56. Han, X., Chen, Z., Zhang, G. and Yu, J.: Surfactant-polymer flooding formulated with commercial surfactants and enhanced by negative salinity gradient, Fuel 274 (2020) 117874. DOI:10.1016/j.fuel.2020.117874

57. Battistutta, E., van Kuijk, S. R., Groen, K. V. and Zitha, P. L. J.: Alkaline-surfactantpolymer (ASP) flooding of crude oil at under-optimum salinity conditions. Proceedings of the SPE Asia Pacific Enhanced Oil Recovery Conference (Paper SPE-174666-MS), Kuala Lumpur, Malaysia, August $11-13,2015$. DOI:10.2118/174666-MS

58. Puerto, M. C., Hirasaki, G. J., Miller, C. A., Reznik, C., Dubey, S., Barnes, J. R. and van Kuijk, S.: Effect of hardness and cosurfactant on phase behavior of alcoholfree alkyl propoxylated sulfate systems, SPE J. 20 (2015) 1145- 1153. DOI:10.2118/169096-PA

59. Aitkulov, A. and Mohanty, K. K.: Investigation of alkaline-surfactant-polymer flooding in a quarter five-spot sandpack for viscous oil recovery, J. Petroleum Sci. Engin. 175 (2019) 706-718. DOI:10.1016/j.petrol.2019.01.018

60. Saxena, N., Goswami, A., Dhodapkar, P. K., Nihalani, M. C. and Mandal, A.: Biobased surfactants for enhanced oil recovery: Interfacial properties, emulsification and rock-fluid interactions, J. Petroleum Sci. Engin. 176 (2019) 299-311. DOI:10.1016/j.petrol.2019.01.052

61. Salehi, M., Johnson, S. J. and Liang, J.-T.: Enhanced wettability alteration by surfactants with multiple hydrophilic moieties, J. Surf. Deterg. 13 (2010) 243-246. DOI:10.1007/s 11743-010-1193-8

62. Samanta, A., Ojha, K., Sarkar, A. and Mandal, A.: Surfactant and surfactantpolymer flooding for enhanced oil recovery. Adv. Petroleum Exploration Devel. 2 (2011) 13-18. DOI:10.3968/j.aped.1925543820110201.608

63. Ko, K. M., Chon, B. H., Jang, S. B. and Jang, H. Y.: Surfactant flooding characteristics of dodecyl alkyl sulfate for enhanced oil recovery, J. Industrial Engin. Chem. 20 (2014) 228-233. DOI:10.1016/j.jiec.2013.03.043

64.Ji, Y., Wang, D., Cao, X., Guo, L. and Zhu, Y.: Both-branched amphiphilic polymer oil displacing system: Molecular weight, surfactant interactions and enhanced oil recovery performance, Colloids Surfaces A 509 (2016) 440-448. DOI:10.1016/j.colsurfa.2016.09.031

65. Ebaga-Ololo, J. and Chon, B. H.: Experimental investigation of the influence of salinity gradient on low-concentration surfactant flooding in Berea sandstone, J. Industr. Engin. Chem. 68 (2018) 355-363. DOI:10.1016/j.jiec.2018.08.007

66. Salager, J.-L., Forgiarini, A. and Marquez, R.: Extended surfactants including an alkoxylated central part intermediate producing a gradual polarity transition A review of the properties used in applications such as enhanced oil recovery and polar oil solubilization in microemulsions, J. Surf. Deterg. 22 (2019) 935-972. DOI: 10.1002/jsde.12331

67. Lv, M., Zhou, Y., Wang, S, Han, F. and Xu, B.: Effects of the polypropylene oxide number on the surface properties of a type of extended surfactants, J. Surf. Deterg. 21 (2018) 335-341. DOI:10.1002/jsde.12039

68. Minana-Pérez, M., Graciaa, A., Lachaise, J. and Salager, J. L.: Solubilization of polar oils in microemulsion systems, Progr. Colloid Polym. Sci. 98 (1995) 177 - 179. DOI:10.1007/BFb0115232

69. Puerto, M., Hirasaki, G. J., Miller, C. A. and Barnes, J. R.: Surfactant systems for EOR in high-temperature, high-salinity environments, SPE J. 17 (2012) 11 - 19. DOI: 10.2118/129675-PA

70. Lindman, B., Medronho, B. and Karlström, G.: Clouding of nonionic surfactants, Curr. Opin. Colloid Interface Sci. 22 (2016) 23-29. DOI:10.1016/j.cocis.2016.01.005

71. Holmberg, K.: Surfactants, in Ullmann's Encyclopedia of Industrial Chemistry, Wiley-VCH, Weinheim, Germany (2019) 5-7. DOI:10.1002/14356007.a25 747.pub2

72. Kronberg, B., Holmberg, $K$. and Lindman, B.: Surface Chemistry of Surfactants and Polymers, Wiley, Chichester, UK (2014) $81-83$. DOI:10.1002/9781118695968

73. Forgiarini, A. M., Scorzza, C., Velasquez, J., Vejar, F., Zambrano, E. and Salager, J.$L .:$ Influence of the mixed propoxy/ethoxy spacer arrangement order and of the ionic head group nature on the adsorption and aggregation of extended surfactants, J. Surf. Deterg. 13 (2010) 451 -458. DOI: 10.1007/s11743-010-1216-5

74. Johannessen, A. M. and Spildo, K.: Enhanced oil recovery (EOR) by combining surfactant with low salinity injection, Energy Fuels 27 (2013) 5738-5749. DOI:10.1021/ef400596b

75. Upamali, K. A. N., Liyanage, P. J., Jang, S. H., Shook, E., Weerasoorlya, U. P. and Pope, G. A.: New surfactants and cosolvents increase oil recovery and reduce cost, SPE J. 23 (2018) 66-83. DOI:10.2118/179702-PA 
76. Solairaj, S., Britton, C., Kim, D. H., Weerasooriya, U. and Pope G. A.: Measurement and analysis of surfactant retention, Proceedings of the 18th SPE Improved Oil Recovery Symposium, Tulsa, OK, April 14- 18, 2012. DOI: 10.2118/154247-MS

77. Chen, Z., Han, X., Kurnia, I., Yu, J., Zhang, G. and Li, L.: Adoption of phase behavior tests and negative salinity gradient concept to optimize Daqing oil field alkaline-surfactant-polymer flooding, Fuel 232 (2018) 71 - 80. DOI:10.1016/j.fuel.2018.05.130

78. Han, X., Kurnia, I., Chen, Z., Yu, J. and Zhang, G.: Effect of oil reactivity on salinity profile design during alkaline-surfactant-polymer flooding, Fuel 254 (2019) 115738. DOI:10.1016/j.fuel.2019.115738

79. Sui, X., Chen, Z., Kurnia, I., Han, X., Yu, J. and Zhang, G.: Alkaline-surfactantpolymer flooding of active oil under reservoir conditions, Fuel 262 (2020) 116647. DOI: 10.1016/j.fuel.2019.116647

80. Holmberg, K.: Surfactants, in Ullmann's Encyclopedia of Industrial Chemistry, Wiley-VCH, Weinheim, Germany (2019) 19. DOI:10.1002/14356007.a25_747.pub2

81. Li, Y., Puerto, M., Bao, X., Zhäng., W., Jin, J., Su, Z., Shen, S., Hirasaki, G. and Miller, $C$.: Synergism and performance for systems containing binary mixtures of anionic/cationic surfactants for enhanced oil recovery, J. Surf. Deterg. 20 (2017) 21 -34. DOI:10.1007/s11743-016-1892-x

82.Zulkifli, N. N., Mahmood, S. M., Akbari, S., Manap, A. A. A., Kechut, N. I. and Elrais, K. A.: Evaluation of new surfactants for enhanced oil recovery applications in high-temperature reservoirs, J. Petroleum Exploration Prod. Technol. 10 (2020) 283-296. DOI:10.1007/s 13202-019-0713-y

83. Liyanage, P. J., Lu, J., Pinnawala Arachchilage, G. W., Weerasooriya, U. P. and Pope, G. A.: A novel class of large-hydrophobe tristyrylphenol (TSP) alkoxy sulfate surfactants for enhanced oil recovery, J. Petroleum Sci. Engin. 128 (2015) 73-85. DOl:10.1016/j.petrol.2015.02.023

84. Nowrouzi, I., Mohammadi, A. H. and Khaksar Manshad, A.: Water-oil interfacial tension (IFT) reduction and wettability alteration in surfactant flooding process using extracted saponin from Anabasis Setifera plant, J. Petroleum Sci. Engin. 189 (2020) 1006901. DOI:10.1016/j.petrol.2019.106901

85. Kumar, S., Saxena, N. and Mandal, A.: Synthesis and evaluation of physicochemical properties of anionic polymeric surfactant derived from Jatropha oil for application in enhanced oil recovery, J. Industrial Engin. Chem. 43 (2016) 106 - 116. DOI:10.1016/j.jiec.2016.07.055

86. Raffa, P., Broekhuis, A. A. and Picchioni, F.: Polymeric surfactants for enhanced oil recovery: A review, J. Petroleum Sci. Engin. 145 (2016) $723-733$. DOI:10.1016/j.petrol.2016.07.007

87. Hamdi, S. S., Al-Kayiem, H. H. and Muhsan, A. S.: Natural polymer non-covalently grafted graphene nanoplatelets for improved oil recovery process: A micromodel evaluation, J. Molecular Liquids 310 (2020) 113076. DOI: 10.1016/j.molliq.2020.113076

88. Yuan, T., Liu, Z., Gao, R., Hu, G., Zhang, G. and Zhao, J.: Enhanced oil recovery from high-salinity reservoirs by cationic gemini surfactants, J. Applied Polym. Sci. 135 (2017) 46086-46092. DOI:10.1002/app.46086

89. Pal., S., Mushtaq, M., Banat, F. and Sumaiti, A. M. A.: Review of surfactant-assisted chemical enhanced oil recovery for carbonate reservoirs: challenges and future perspectives, Petroleum Sci. 15 (2018) 77- 102. DOI: 10.1007/s 12182-017-0198-6

90. Vatanparast, H., Alizadeh, A. H., Bahramian, A. and Bazdar, H.: Wettability alteration of low-permeable carbonate reservoir rocks in presence of mixed ionic surfactants, Petroleum Sci. Technol. 29 (2011) 1873 - 1884. DOI: $10.1080 / 10916461003610389$

91. Sharma $H$. and Mohanty K.: Wettability alteration in high-temperature and high salinity carbonate reservoirs, SPE J. 18 (2013) 646-655. DOI: $10.2118 / 147306-P A$

92. Rosen, M. J. and Kunjappu, J. T.: Surfactants and Interfacial Phenomena, 4th Ed., Wiley, Hoboken, NJ (2012) 421 - 457;. DOI: 10.1002/9781118228920

93. Kronberg, B., Holmberg, K. and Lindman, B.: Surface Chemistry of Surfactants and Polymers, Wiley, Chichester, UK (2014) 251 -269. DOI:10.1002/9781118695968

94. Khan, A. and Marques, E.: Catanionic surfactants, in Robb, I. D. (Ed.), Specialist Surfactants, Springer, Dordrecht, Germany (1997) 37-80. DOI: 10.1007/978-94-009-1557-2 3

95.Li, Y., Zhang, W., Kong, B., Puerto, M., Bao, X, Sha, O., Shen, Z., Yang, Y., Liu, Y., Gu, S., Miller, C. and Hirasaki, G.: Mixtures of anionic/cationic surfactants: A new approach for enhanced oil recovery in low-salinity, high-temperature sandstone reservoir, SPE J. 21 (2016) 1164-1177. DOI:10.2118/169051-PA

96. Wang, D., Liu, C., Wu, W. and Wang, G.: Novel surfactants that attain ultra-low interfacial tension between oil and high salinity formation water without adding alkali, salts, co-surfactants, alcohols and solvents, Proceedings of the SPE EOR Conference at Oil \& Gas West Asia (Paper 127452-MS) Muscat, Oman, April 11 - 13, 2010. DOl:10.2118/127452-MS

97. Kumar, A. and Mandal, A.: Critical investigation of zwitterionic surfactant for enhanced oil recovery from both sandstone and carbonate reservoirs: Adsorption, wettability alteration and imbibition studies, Chem. Engin. Sci. 209 (2019) 115222. DOI:10.1016/j.ces.2019.115222

98.Dong, Z., Zheng, Y. and Zhao, J.: Synthesis, physico-chemical properties and enhanced oil recovery flooding evaluation of novel zwitterionic gemini surfactants, J. Surf. Deterg. 17 (2014) 1213-1222. DOI: 10.1007/s 11743-014-1616-Z

99. Kurnia, I., Zhang, G., Han, X. and Yu, J.: Zwitterionic-anionic surfactant mixture for chemical enhanced oil recovery without alkali, Fuel 259 (2020) 116236. DOI: 10.1016/j.fuel.2019.116236
100. Rosen, M. J. and Kunjappu, J. T.: Surfactants and Interfacial Phenomena, 4th Ed., Wiley, Hoboken, NJ (2012) 141 - 157. DOI:10.1002/9781118228920

101. Feng, H., Kang, W., Zhang, L., Chen, J., Li, Z., Zhou, Q. and Wu, H.: Experimental study on a fine emulsion flooding system to enhance oil recovery for low permeability reservoirs, J. Petroleum Sci. Engin. 171 (2018) 974-981. DOI:10.1016/j.petrol.2018.08.011

102. Tackie-Otoo, B. N., Mohammed, M. A. A., Yekeen, N. and Negash, B. M.: Alternative chemical agents for alkalis, surfactants and polymers for enhanced oil recovery: Research trends and prospects, J. Petroleum Sci. Engin. 187 (2020) 106828. DOI:10.1016/j.petrol.2019.106828

103. Ding, M. C., Wang, Y., Li, Z., Zhong, D., Yuan, F. and Zhu, Y.: The role of IFT and emulsification in recovering heavy oil during S/SP flooding, J. Industr. Engin. Chem. 77 (2019) 198-208. DOl:10.1016/j.jiec.2019.04.036

104. Iglauer, S., Wu, Y., Shuler, P., Tang, Y. and Goddard III, W. A.: New surfactant classes for enhanced oil recovery and their tertiary oil recovery potential, J. Petroleum Sci. Engin. 71 (2010) 23-29. DOI:10.1016/j.petrol.2009.12.009

105. Sahni, V., Dean, R. M., Britton, C., Kim, D. H., Weerasooriya, U. and Pope, G. A. The role of co-solvents and co-surfactants in making chemical floods robust, Proceedings of the SPE Improved Oil Recovery Symposium, Tulsa, OK, April 24-28, 2010. DOI: 10.2118/130007-MS

Received: 21.12 .2020

Accepted: 06.01.2021

\section{Bibliography}

DOI 10.1515/tsd-2020-2340

Tenside Surf. Det. 58 (2021) 3, page 164- 176

(C) 2021 Walter de Gruyter GmbH, Berlin/Boston, Germany

ISSN 0932-3414 · e-ISSN 2195-8564

\section{Correspondence address}

Professor Krister Holmberg

Chalmers University of Technology

Department of Chemistry and Chemical Engineering

SE-412 96 Gothenburg

Sweden

Tel.: +46-730-794215

E-mail: krister.holmberg@chalmers.se

\section{Associate Professor Lu Ming}

Qingdao Institute of Bioenergy and Bioprocess Technology

Chinese Academy of Sciences

Songling Road 189

Laoshan District

Qingdao

China 266101

Tel: +86-186-61617301

E-mail: Ivming@qibebt.ac.cn

\section{The authors of this paper}

The first corresponding author, Krister Holmberg is Professor Emeritus at Chalmers University of Technology in Gothenburg, Sweden. Before he joined Chalmers in 1998 he was Director of the Institute for Surface Chemistry in Stockholm, Sweden. He has been active in surfactant related research since long back and he has published 315 scientific papers and written or edited 7 books. One of his recent papers is a long chapter titled Surfactants in Ullmann's Encyclopedia of Industrial Chemistry.

The second corresponding author, Ming Lu is Associate Professor at the Chinese Academy of Sciences in Qingdao, China. He took his Ph. D. at Pusan National University in Busan, South Korea in 2010. He was then postdoc at New York University, Pusan National University and Kansas State University before joining Qingdao Institute of Bioenergy and Bioprocess Technology belonging to Chinese Academy of Sciences in Qingdao in 2014. Dr. Lu is also affiliated to the company Ginzre New Materials Development as Chief Technology Officer.

Xu Han took his Ph.D. at New Mexico Institute of Mining and Technology in 2020. $\mathrm{He}$ is now a researcher at PetroChina in Beijing working on enhanced oil recovery.

Yixuan Fan is a graduate student at Qingdao Institute of Bioenergy and Bioprocess Technology belonging to Chinese Academy of Sciences in Qingdao.

Yuxi Li is a graduate student at the University of Portsmouth, UK. 